Terbit online pada laman web jurnal : http://teknosi.fti.unand.ac.id/

\title{
Penerapan Algoritma Floyd Warshall dalam Aplikasi Penentuan Rute Terpendek Mencari Lokasi BTS (Base Tower Station) pada PT.GCI Palembang
}

\author{
Vera Apriliani Nawagusti ${ }^{a}$ \\ ${ }^{a}$ Jurusan Teknik Elektro, Program Studi Teknik Telekomunikasi, Politeknik Negeri Sriwijaya, Jl. Srijaya Negara Bukit Besar, Kota Palembang, Sumatera \\ Selatan 30139, Indonesia
}

\begin{tabular}{|c|}
\hline INFORMASI ARTIKEL \\
\hline $\begin{array}{l}\text { Sejarah Artikel: } \\
\text { Diterima Redaksi: } 00 \text { Februari } 00 \\
\text { Revisi Akhir: } 00 \text { Maret } 00 \\
\text { Diterbitkan Online: } 00 \text { April } 00\end{array}$ \\
\hline KATA KUNCI \\
\hline $\begin{array}{l}\text { Pencarian Rute Terpendek, } \\
\text { Algoritma Floyd Warshall, } \\
\text { Graf, } \\
\text { PT.GCI Palembang }\end{array}$ \\
\hline KORESPONDENSI \\
\hline $\begin{array}{l}\text { Telepon: } 082184926168 \\
\text { E-mail: veraaprilianin97@gmail.com }\end{array}$ \\
\hline
\end{tabular}

\section{A B S T R A C T}

For PT.GCI Palembang optimization of the shortest route is needed in the process of finding the location of BTS (Base Tower Station) because with the optimization of the shortest route determination can assist the technician in optimizing the distance to the location of BTS needs to be done maintenance and repair so as to increase the efficiency of time and the required costs. The shortest route problem is a problem in finding the path between two vertices on a weighted graph that has a combined value of the number of weights on the side of the graph passed by the minimum number. In this research using Floyd Warshall algorithm to determine the shortest route. Where the Floyd Warshall algorithm can compare all track opportunities in the graph for each side of all the nodes it passes to the least amount. Based on the results of calculations from this research obtained the shortest route that is from point $1-4-3-2$ that is equal to $10,9 \mathrm{~km}$

\section{PENDAHULUAN}

PT.GCI Palembang adalah sebuah perusahaan yang menyediakan produk dan layanan berupa Radio Network Planning and Optimization, UMTS/CDMA/GSM CW testing Propagation Model Tuning, In-building System Design and Implementation Managed Service Operations \& Maintenance (O\&M), dan BTS \& MW \& Core Engineering Service [1]. PT.GCI Palembang juga bekerjasama dengan perusahaan lain dalam mengerjakan beberapa project operator telepon seluler. Salah satunya project perawatan BTS (Base Tower Station) milik operator telepon seluler seperti 3 yang tersebar di seluruh wilayah kota Palembang. Agar kualitas sinyal dari jaringan BTS tetap terjaga, maka PT.GCI Palembang harus tetap melakukan pemeriksaan dan perawatan terhadap BTS tersebut. Oleh karena itu dibutuhkan sebuah aplikasi penentuan rute terpendek antar BTS di kota Palembang yang dapat berjalan pada platform android, agar dapat membantu teknisi dalam mengoptimalkan jarak tempuh menuju lokasi BTS apabila terjadi suatu kerusakan dan perawatan pada BTS tersebut.

https://doi.org/10.25077/ TEKNOSI.v4i2.2018.081-088
Location Based Service (LBS) merupakan suatu layanan yang dapat digunakan untuk mengetahui posisi berdasarkan titik geografis dari lokasi pengguna dan lokasi lain yang diinginkan menggunakan suatu perangkat mobile [2]. Teknologi berupa posisi ini selanjutnya dikembangkan menjadi layanan penentuan rute terpendek. Teori graf dapat memecahkan permasalahan rute terpendek. Menurut teori graf, permasalahan rute terpendek dapat diartikan sebagai suatu permasalahan dalam menemukan lintasan antara dua buah simpul pada graf berbobot pada sisi graf yang dilintasi dengan jumlah yang paling minimum [3].

Terdapat beberapa metode algoritma yang dapat diterapkan untuk menyelesaikan permasalahan penentuan rute tependek seperti Dijkstra, Bellman-Ford, Floyd Warshall, dan lain sebagainya. Algoritma Dijkstra lebih cepat dalam menemukan rute terpendek, namun algoritma Dijkstra hanya memikirkan solusi terbaik yang akan diambil pada setiap langkah tanpa memikirkan konsekuensinya ke depan serta pada algoritma Dijkstra tidak dapat mengatasi graf berbobot negatif [4][5]. Sedangkan pada algoritma Bellman-Ford dapat menjamin ditemukannya solusi optimum global dengan menggunakan perhitungan pohon ruang status namun pada algoritma Bellman-Ford membutuhkan waktu

Attribution-NonCommercial 4.0 International. Some rights reserved 
yang lebih lama dibandingkan dengan algoritma Dijkstra [6]. Pada algoritma Floyd Warshall yang menerapkan program dinamis lebih menjamin keberhasilan dalam penemuan solusi lintasan terpendek, karena algoritma ini dapat membandingkan semua kemungkinan lintasan pada graf untuk setiap sisi dari semua simpul yang dilewati [7][8].

Berdasarkan hal tersebut, pada penelitian ini solusi yang digunakan dalam kasus penyelesaian penentuan rute terpendek dalam mencari lokasi BTS (Base Tower Station) pada PT.GCI Palembang diselesaikan dengan menerapkan algoritma Floyd Warshall. Aplikasi penentuan rute terpendek mencari lokasi BTS di PT.GCI Palembang dengan menerapkan algoritma Floyd Warshall ini bertujuan untuk membantu teknisi dalam mengoptimalkan jarak tempuh menuju lokasi BTS apabila terjadi suatu kerusakan dan perawatan pada BTS tersebut.

Berdasarkan uraian diatas, maka dirumuskan beberapa permasalahan, yaitu :

1. Bagaimana proses tampilan pada aplikasi penentuan rute terpendek mencari lokasi BTS di kota Palembang?

2. Bagaimana melakukan perhitungan menggunakan teori graf dengan menerapkan algoritma Floyd Warshall dalam menentukan rute terpendek mencari lokasi BTS di kota Palembang ?

Untuk mendapatkan hasil yang optimal dalam penelitian ini, maka diberikan batasan-batasan penelitian sebagai berikut :

1. BTS yang dipetakan pada aplikasi ini terletak di wilayah kota Palembang.

2. Aplikasi ini berjalan pada platform android.

3. Aplikasi ini menerapkan algoritma Floyd Warshall dalam pencarian rute terpendek.

4. Sumber data lokasi-lokasi BTS didapatkan dari PT.GCI Palembang.

Adapun tujuan yang ingin dicapai pada penelitian ini adalah untuk merancang suatu aplikasi penentuan rute terpendek yang menerapkan algoritma Floyd Warshall dalam mencari lokasi BTS pada PT.GCI Palembang, sehingga dapat mengoptimalkan jarak tempuh teknisi dalam menuju lokasi BTS yang menjadi tujuan.

\section{TINJAUAN PUSTAKA}

\subsection{Location Based Service (LBS)}

Qusay H.Mahmoud menyatakan bahwa Location Based Service (LBS) merupakan layanan yang berguna untuk mengetahui posisi dari pengguna, dimana informasi tersebut digunakan untuk menyediakan jasa dan aplikasi personal [5]. Terdapat 2 pendekatan dasar yang digunakan untuk pengaplikasian LBS, yaitu [5] :

1. memproses data lokasi di server dan mengirimkan hasilnya ke alat.

2. Memperoleh data lokasi dari alat tersebut menurut aplikasi yang menggunakannya secara langsung

Beberapa pendekatan yang digunakan aplikasi dalam mendapatkan posisi dari pengguna, antara lain :

1. Memanfaatkan jaringan telepon seluler, dimana tingkat ketepatan aplikasi dalam mendeteksi posisi berdasarkan

82 Vera Apriliani Nawagusti ukuran dari sel dan memungkinkan tingkat akurasi yang lebih rendah.

2. Memanfaatkan satelit, dengan mengaplikasikan GPS dalam mendapatkan informasi posisi yang akurat.

\subsection{Global Positioning System (GPS)}

Global Positioning System atau yang dikenal dengan GPS, merupakan suatu alat atau sistem yang berfungsi untuk menginformasikan posisi pengguna di permukaan bumi yang berbasiskan satelit. Informasi dikirim dari satelit berupa sinyal radio dengan data digital [4]. Posisi unit GPS ditetapkan berdasarkan titik koordinat latitude dan longitude.

\subsection{Graf}

Graf dapat digunakan dalam menyelesaikan permasalahan rute terpendek. Menurut teori graf, permasalahan rute terpendek didefinisikan sebagai suatu persoalan dalam menemukan lintasan antara dua buah simpul pada graf berbobot yang memiliki jumlah yang paling minimum dari jumlah bobot pada sisi graf yang dilintasi [3]. Suatu graf G terdiri dari dua himpunan graf, yaitu himpunan $\mathrm{V}$ dan himpunan $\mathrm{E}$, dimana $\mathrm{V}$ merupakan himpunan tak kosong dari simpul-simpul, sedangkan E merupakan sisi yang menghubungkan sepasang simpul [9].

Berikut ini proses sebuah graf dibentuk untuk menggambarkan lokasi-lokasi dalam menyelesaikan persoalan rute terpendek [10]:

1. Gabungkan tiap titik dari setiap rute menjadi sebuah connected graph (graf terhubung).

2. Berikan arah lintasan pada rute sebagai aliran (flow) sehingga terbentuk suatu directed graph dari connected graph yang ada.

3. Informasi dari jarak tempuh yang didapatkan diubah menjadi bobot jarak. Implementasikan bobot jarak yang ada menjadi sebuah aliran beban directed graph sehingga menjadi sebuah weighted graph (graf berbobot).

Representasi Graf

Berikut ini representasi dari graf antara lain [9] :

1. Adjacency Matrix

Sebuah matriks digunakan untuk menunjukkan adjacency set dari setiap verteks dalam baris dan kolomnya. Dimana baris pada matriks menunjukkan nomor verteks adjacency berasal sedangkan kolom pada matriks menunjukkan nomor verteks kemana arah adjacency. Elemen matriks $[\mathrm{x}, \mathrm{y}]$ bernilai 1 apabila terdapat sisi dari $\mathrm{x}$ ke $\mathrm{y}$, namun bernilai 0 apabila terdapat lintasan yang berawal dan berakhir pada simpul yang sama.

2. Adjacency List

Pada adjacency list representasi matriksnya berupa matriks sparse, dimana sebagian besarnya berisikan bilangan nol. Untuk efisiensi ruang, tiap baris pada matriks digantikan list yang hanya terdapat verteks-verteks dalam adjacency set $\mathrm{Vx}$ dari setiap verteks $\mathrm{x}$.

\subsection{Algoritma Floyd Warshall}

Algoritma Floyd Warshall merupakan pemrograman dinamis yang melakukan penyelesaian masalah dengan melihat solusi yang akan diperoleh sebagai suatu keputusan yang saling terkait. Prinsip optimalitas ialah prinsip yang diterapkan oleh 
pemrograman dinamis, yaitu jika solusi total optimal, maka bagian solusi sampai suatu tahap (misalnya tahap ke-i) juga optimal [8].

Algoritma Floyd Warshall memiliki input graf berarah dan berbobot. Serta output dari algoritma Floyd Warshall adalah dengan menghitung bobot terkecil dari semua lintasan yang menghubungkan sebuah pasangan titik, dan melakukannya sekaligus untuk semua pasangan titik [9].

Berikut ini digunakan Formulasi Rekrusif untuk algoritma Floyd Warshall antara lain [9] :

1. Vertex-vertex antara dalam short path

2. Jika $\mathrm{V}=\{1,2,3, . ., \mathrm{N})$, untuk $\mathrm{k}=0, \ldots ., \mathrm{n}$. Maka $\mathrm{d}_{\mathrm{ij}}{ }^{(\mathrm{k})}=$

- $\quad w_{\text {ij jika } k=0}$

- $\quad \min \left(\mathrm{d}_{\mathrm{ij}}{ }^{(\mathrm{k}-1)}, \mathrm{d}_{\mathrm{ik}}{ }^{(\mathrm{k}-1)}+\mathrm{d}_{\mathrm{ij}}{ }^{(\mathrm{k}-1)}\right.$, untuk $\mathrm{k}>0$

3. Solusi dari $\mathrm{d}_{\mathrm{ij}}(\mathrm{n})$ merupakan matriks shortest path dari vertex $i$ ke vertex $j$.

Gambar 1 menampilkan Pseudocode dari algoritma Floyd Warshall.

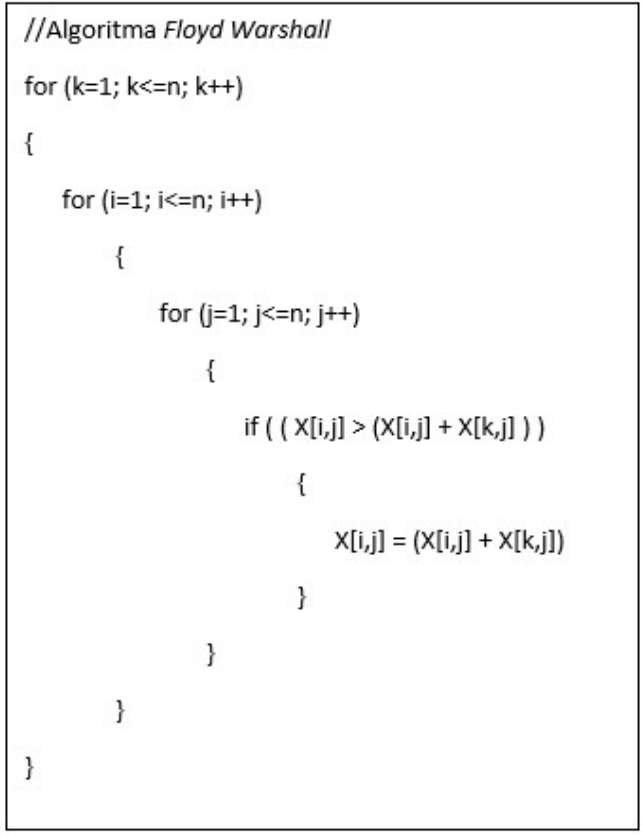

Gambar 1. Pseudocode Algoritma Floyd Warshall [8]

\subsection{Google Maps API}

Google Maps API adalah sebuah layanan (service) yang diberikan oleh Google kepada para pengguna untuk memanfaatkan Google Maps dalam mengembangkan aplikasi [11]. Google Maps API menyediakan beberapa fitur untuk memanipulasi peta, dan menambah konten melalui berbagai jenis services yang dimiliki, serta mengijinkan kepada pengguna untuk membangun aplikasi enterprise di dalam websitenya [11].

\section{METODOLOGI}

Perancangan aplikasi pada penelitian ini terbagi menjadi dua bagian yaitu perancangan tampilan (.xml) dan perancangan perintah program (.java). Perancangan tersebut diawali dengan perancangan tampilan aplikasi. Didalam penelitian ini, desain tampilan yang dirancang akan diuji coba apakah sudah sesuai dengan yang diharapkan. Setelah pengujian tersebut, dilakukan perancangan perintah program pada aplikasi. Seperti halnya pada perancangan tampilan, pengujian juga akan dilakukan pada perintah program aplikasi.

\subsection{Perancangan Desain Tampilan Aplikasi}

Perancangan tampilan ialah perancangan untuk tampilan aplikasi yang dilakukan pada layout yang terdapat pada aplikasi android studio. Pembuatan desain aplikasi dapat dilakukan pada file XML atau Graphical Layout di dalam software. Pada layout terdapat pilihan widget seperti button, text, images, dan lain-lain yang dapat diatur sesuai dengan desain yang kita inginkan. Pada file $\mathrm{XML}$, widget dapat diatur menggunakan coding sedangkan pada graphical layout, widget dapat diatur secara manual.

\subsubsection{Rancangan Tampilan Menu Utama}

Pada perancangan ini, terdapat menu input nama BTS, dimana pada menu ini akan diinput nama-nama BTS yang mengalami kerusakan. Pada menu input nama BTS, tampilannya akan diatur menggunakan widget berupa button. Button tersebut berupa button $O K$ dan cancel. Button OK, akan ditampilkan beberapa list nama BTS yang mengalami kerusakan, sedangkan button cancel, digunakan untuk membatalkan list nama BTS yang akan diinput. Rancangan tampilan utama dapat dilihat pada Gambar 2.

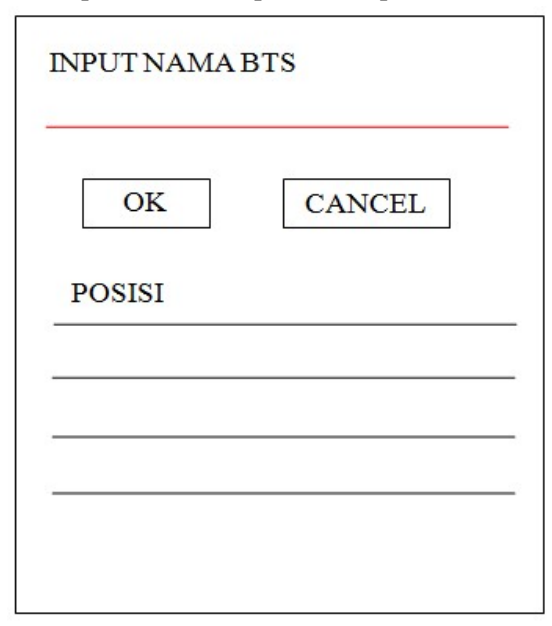

Gambar 2. Rancangan Tampilan Menu Input Nama BTS

\subsubsection{Rancangan Tampilan Floyd Warshall}

Pada perancangan ini akan menampilkan rute terpendek dari hasil perhitungan menggunakan algoritma Floyd Warshall. 


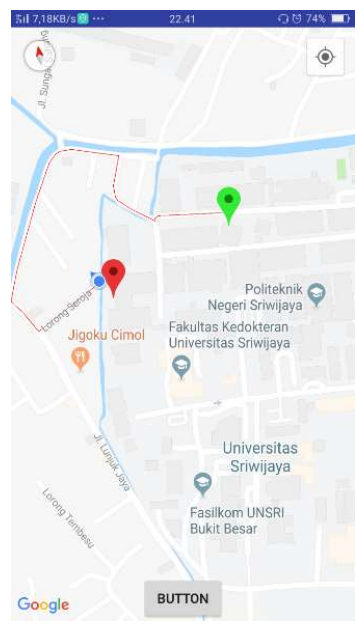

\subsection{Perancangan Perintah Aplikasi}

Pada perancangan ini dilakukan proses penentuan rute terpendek menggunakan algoritma Floyd Warshall. Berikut ini flowchart dari perancangan perintah program menu algoritma Floyd Warshall yang dapat terlihat pada Gambar 4.

\section{HASIL DAN PEMBAHASAN}

Pada tahapan ini merupakan tahapan dimana didapatkan hasil dari perancangan layout yang telah diimplementasikan kedalam program yang dibuat dengan menggunakan android studio seperti yang terlihat pada Gambar 5 dan 6, sehingga menjadi sebuah aplikasi penentuan rute terpendek dalam mencari lokasi BTS (Base Tower Station) di kota Palembang.

Gambar 3. Rancangan Tampilan Menu Floyd Warshall

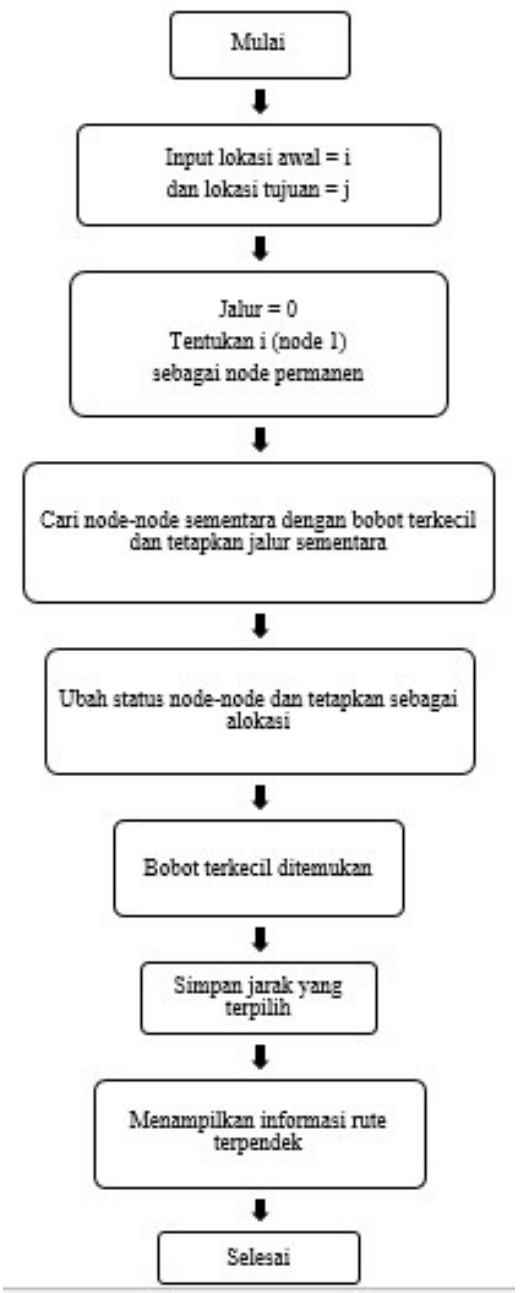

Gambar 4. Flowchart Perancangan Perintah Program Algoritma Floyd Warshall

\subsection{Tampilan Aplikasi}

Pada penelitian ini didapatkan 2 tampilan dari aplikasi penentuan rute terpendek mencari lokasi BTS (Base Tower Station) di kota Palembang, yang terdiri dari tampilan menu input nama BTS, seperti pada Gambar 5 dan tampilan menu Floyd Warshall pada Gambar 6. 


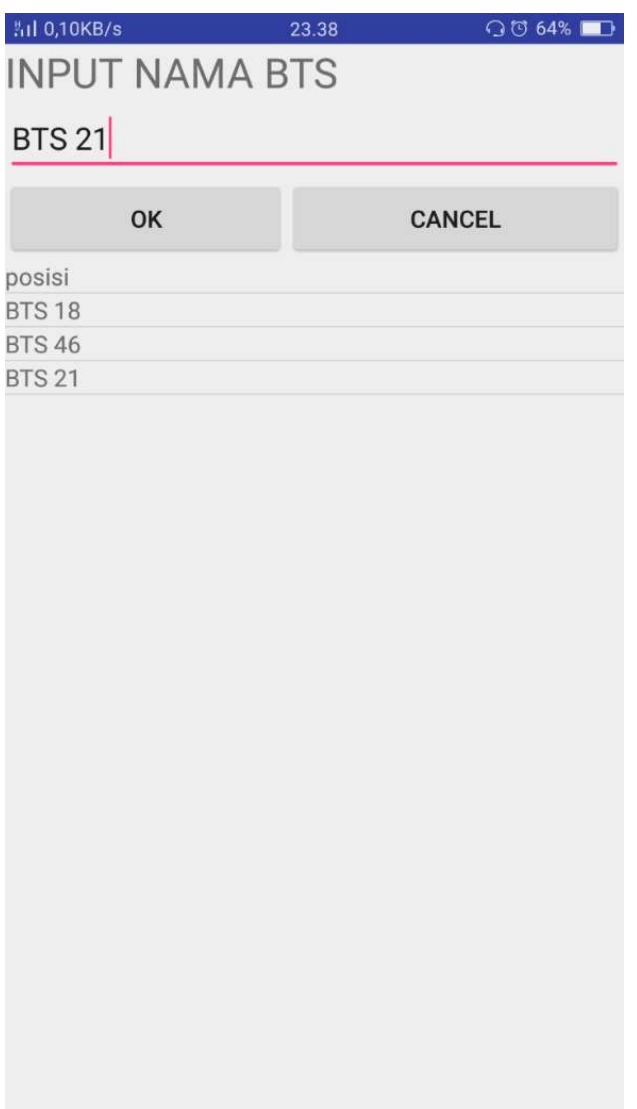

Gambar 5. Tampilan Menu Input Nama BTS

Gambar 5 menunjukkan tampilan menu input nama BTS, dimana nama-nama BTS yang diinput merupakan letak pin lokasi BTS yang perlu dilakukan perawatan maupun perbaikan seperti pada kasus ini BTS yang perlu dilakukan perbaikan maupun perawatan yaitu BTS 18, BTS 46, dan BTS 21. Sedangkan posisi merupakan lokasi teknisi saat ini yang terbaca secara otomatis oleh GPS pada smartphone teknisi.

Pada Gambar 6 merupakan tampilan menu Floyd Warshall, dimana pada menu ini merupakan hasil rute terpendek yang dihasilkan dengan menerapkan perintah program algoritma Floyd Warshall pada android studio.

\subsection{Pengujian Aplikasi}

Pada penelitian ini dilakukan pengujian terhadap penentuan rute terpendek menuju lokasi tujuan. Pengujian ini dilakukan dengan cara perhitungan secara manual untuk melihat apakah proses penentuan rute terpendek pada aplikasi yang dibuat sudah sesuai teori graf dengan menerapkan algoritma Floyd Warshall atau tidak.

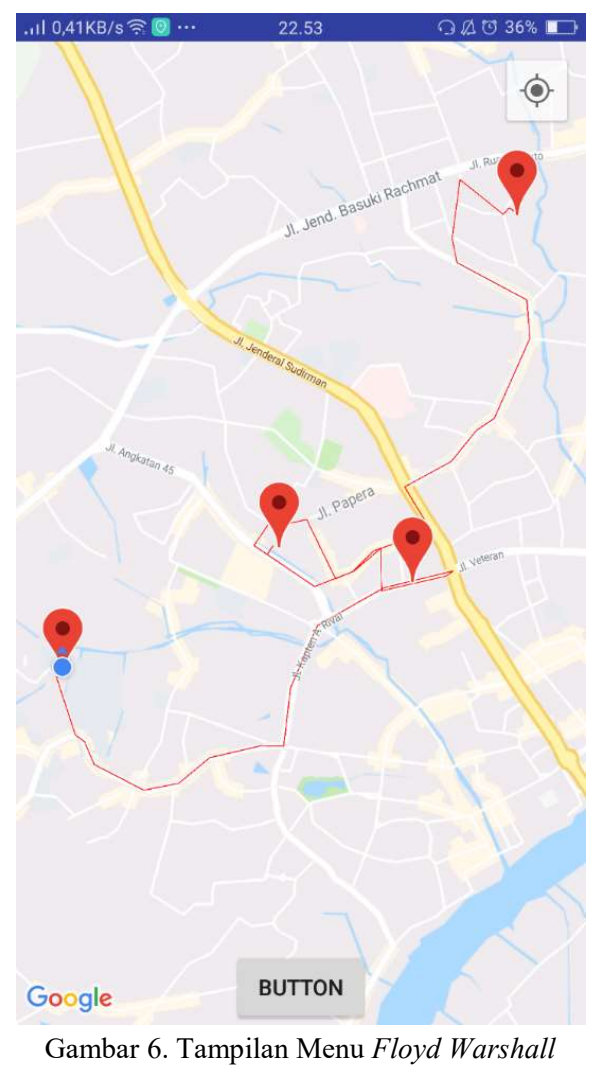

Berikut pengujian rute terpendek pada penelitian ini : misalkan teknisi akan melakukan perawatan pada BTS 18, BTS 21, dan BTS 46, dimana titik 1 diasumsikan sebagai posisi awal teknisi yang dapat kita lihat pada gambar 6 terdapat titik biru, dan titik 2 sebagai BTS 18 yang terletak di Jl. Orde Baru atau jika dilihat pada gambar 6 lokasi pin terletak di sekitar Jl. Jend. Basuki Rachmat, titik 3 sebagai BTS 21 yang terletak di Jl. Angkatan 45, dan titik 4 sebagai BTS 46 yang terletak di Jl. Kapten A. Rivai. Dengan menerapkan metode algoritma Floyd Warshall dalam mencari rute terpendek dari titik 1 menuju ke titik 2, 3, dan 4, didapatkan bahwa :

Tabel dibawah ini menunjukkan data jarak lokasi BTS 18, BTS 21 dan BTS 46.

Tabel 1. Lokasi BTS (Base Tower Station)

\begin{tabular}{|c|c|c|c|}
\hline $\begin{array}{l}\text { Nama } \\
\text { BTS }\end{array}$ & Alamat BTS & Latitude & Longitude \\
\hline BTS 18 & $\begin{array}{l}\text { Jl. Orde Baru/ } \\
\text { Rawasari }\end{array}$ & -2.95573 & 104.75804 \\
\hline BTS 21 & J1. Angkatan 45 & -2.97552778 & 104.7438611 \\
\hline BTS 46 & $\begin{array}{l}\text { J1. Kapten A. } \\
\text { Rivai }\end{array}$ & -2.9776 & 104.7518 \\
\hline
\end{tabular}

Tabel 2. Jarak Antar Lokasi BTS (Base Tower Station)

\begin{tabular}{lll}
\hline Lokasi Awal & Lokasi Tujuan & Jarak (km) \\
\hline 1 & 2 & $7,5 \mathrm{~km}$ \\
1 & 3 & $3,8 \mathrm{~km}$ \\
1 & 4 & $4,2 \mathrm{~km}$ \\
2 & 4 & $3,4 \mathrm{~km}$ \\
3 & 2 & $4,8 \mathrm{~km}$ \\
4 & 3 & $1,9 \mathrm{~km}$ \\
\hline
\end{tabular}


Berikut ini ditampilkan ilustrasi dari suatu graf berbobot yang merepresentasikan jarak antar titik lokasi BTS yang ditunjukkan pada Gambar 7 :

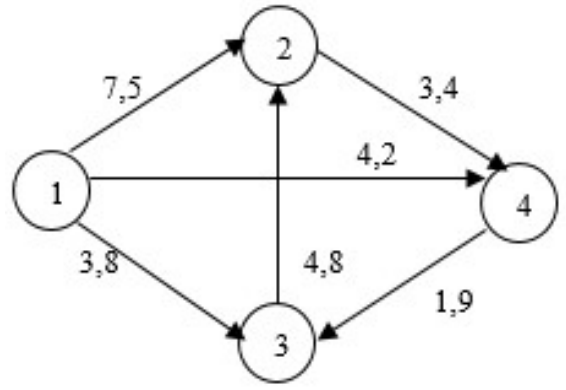

Gambar 7. Graf berbobot jarak antar titik

Berikut ini tahapan perhitungan algoritma Floyd Warshall dalam menentukan rute terpendek yang digambarkan melalui matriks. Dimana baris pada matriks menunjukkan lokasi awal dan kolom pada matriks menunjukkan lokasi tujuan.

Dari Gambar 6, didapat :

$$
\begin{array}{ll}
\mathrm{K} & =0,1,2,3,4 \\
\mathrm{i} & =1,2,3,4 \\
\mathrm{j} & =1,2,3,4
\end{array}
$$

Matriks hubung graf, $\mathrm{K}=0$

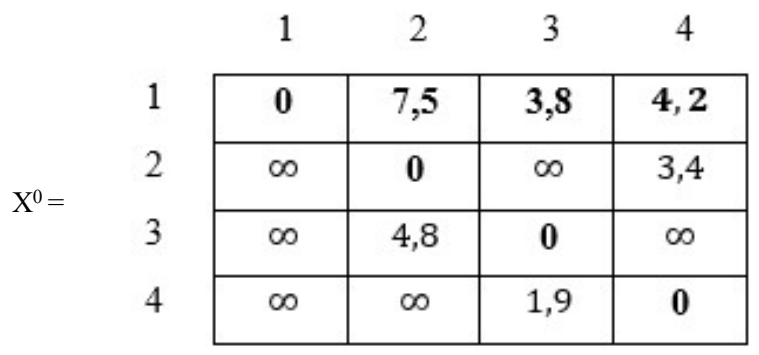

\begin{tabular}{|c|c|c|c|c|c|}
\hline \multirow{5}{*}{$X^{1}=$} & & 1 & 2 & 3 & 4 \\
\hline & 1 & 0 & 7,5 & 3,8 & 4,2 \\
\hline & 2 & $\infty$ & 0 & $\infty$ & 3,4 \\
\hline & 3 & $\infty$ & 4,8 & 0 & $\infty$ \\
\hline & 4 & $\infty$ & $\infty$ & 1,9 & 0 \\
\hline
\end{tabular}

Gambar 8. Matriks hubung $\mathrm{K}=0$

Matriks hubung graf, $\mathrm{K}=1$

Gambar 9. Matriks hubung $\mathrm{K}=1$

Rumus $\quad: \mathrm{X}[\mathrm{i}, \mathrm{j}] \leq \mathrm{X}[\mathrm{i}, \mathrm{k}]+\mathrm{X}[\mathrm{k}, \mathrm{j}]$

Penyelesaian :

$$
\text { - } \quad \mathrm{X}^{0}[2,3] \quad \mathrm{X}^{0}[2,1]+\mathrm{X}^{0}[1,3]
$$

86 Vera Apriliani Nawagusti
- $\mathrm{X}^{0}[2,4] \quad \mathrm{X}^{0}[2,1]+\mathrm{X}^{0}[1,4]$

$3,4<\infty+4,2$

- $\mathrm{X}^{0}[3,2] \quad \mathrm{X}^{0}[3,1]+\mathrm{X}^{0}[1,2]$

$$
4,8<\infty+7,5
$$

- $\mathrm{X}^{0}[3,4] \quad \mathrm{X}^{0}[3,1]+\mathrm{X}^{0}[1,4]$

$$
\infty \quad \infty+4,2
$$

- $\mathrm{X}^{0}[4,2] \quad \mathrm{X}^{0}[4,1]+\mathrm{X}^{0}[1,2]$

$$
\infty=\infty+7,5
$$

- $\quad \mathrm{X}^{0}[4,3] \quad \mathrm{X}^{0}[4,1]+\mathrm{X}^{0}[1,3]$

$$
1,9<\infty+3,8
$$

Matriks hubung graf, $\mathrm{K}=2$

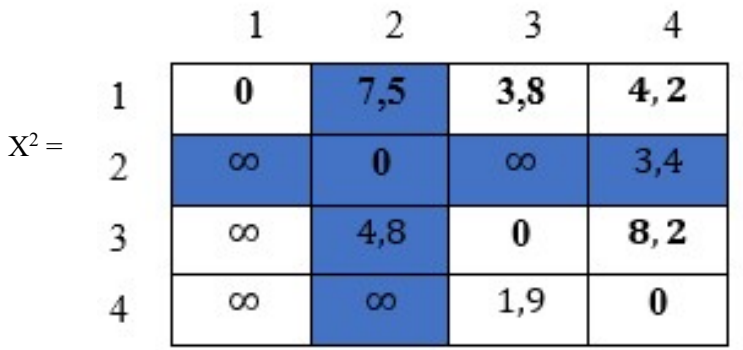

Gambar 10. Matriks hubung $K=2$

Penyelesaian :

- $\mathrm{X}^{1}[1,3] \quad \mathrm{X}^{1}[1,2]+\mathrm{X}^{1}[2,3]$

$$
3,8<7,5+\infty
$$

- $\mathrm{X}^{1}[1,4] \quad \mathrm{X}^{1}[1,2]+\mathrm{X}^{1}[2,4]$

$$
4,2<7,5+3,4
$$

- $\mathrm{X}^{1}[3,1] \quad \mathrm{X}^{1}[3,2]+\mathrm{X}^{1}[2,1]$

$\infty<4,8+\infty$

- $\mathrm{X}^{1}[3,4] \quad \mathrm{X}^{1}[3,2]+\mathrm{X}^{1}[2,4]$

$$
8,2=4,8+3,4
$$

- $\mathrm{X}^{1}[4,1] \quad \mathrm{X}^{1}[4,2]+\mathrm{X}^{1}[2,1]$

$$
\infty \quad=\infty+\infty
$$

- $\mathrm{X}^{1}[4,3] \quad \mathrm{X}^{1}[4,2]+\mathrm{X}^{1}[2,3]$

$$
1,9<\infty+\infty
$$

Matriks hubung graf, $\mathrm{K}=3$

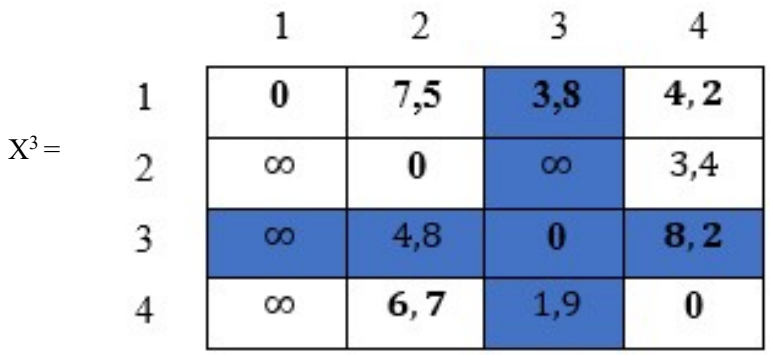

Gambar 11. Matriks hubung $\mathrm{K}=3$ https://doi.org/10.25077/ TEKNOSI.v4i2.2018.081-088 
Penyelesaian :

$$
\begin{array}{cccc}
\text { - } & X^{2}[1,2] & X^{2}[1,3]+X^{2}[3,2] \\
& 7,5 & < & 3,8+4,8 \\
\text { - } & X^{2}[1,4] & X^{2}[1,3]+X^{2}[3,4] \\
& 4,2 & < & 3,8+8,2 \\
\text { - } & X^{2}[2,1] & X^{2}[2,3]+X^{2}[3,1] \\
& \infty & = & \infty+\infty \\
\text { - } & X^{2}[2,4] & & X^{2}[2,3]+X^{2}[3,4] \\
& 3,4 & < & \infty \\
\text { - } & X^{2}[4,1] & X^{2}[4,3]+X^{2}[3,1] \\
& \infty & 1,9+\infty \\
\text { - } & X^{2}[4,2] & \left.X^{1} 24,3\right]+X^{2}[3,2] \\
& 6,7 & < & 1,9+4,8
\end{array}
$$

Matriks hubung graf, $\mathrm{K}=4$

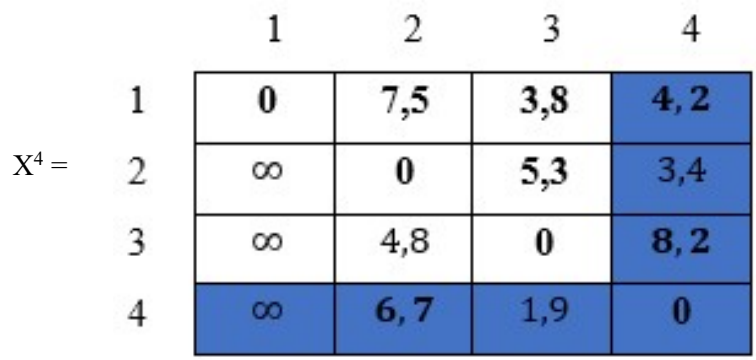

Gambar 12. Matriks hubung $K=4$

Penyelesaian :

- $\quad X^{3}[1,2] \quad X^{3}[1,4]+X^{3}[4,2]$

$7,5<4,2+6,7$

- $\mathrm{X}^{3}[1,3] \quad \mathrm{X}^{3}[1,4]+\mathrm{X}^{3}[4,3]$

$$
3,8<4,2+1,9
$$

- $\quad \mathrm{X}^{3}[2,1] \quad \mathrm{X}^{3}[2,4]+\mathrm{X}^{3}[4,1]$

$\infty \quad=3,4+\infty$

- $\quad X^{3}[2,3] \quad X^{3}[2,4]+X^{3}[4,3]$

$$
5,3=3,4+1,9
$$

- $\quad X^{3}[3,1] \quad X^{3}[3,4]+X^{3}[4,1]$

$$
\infty \quad=8,2+\infty
$$

- $\quad X^{3}[3,2] \quad X^{3}[3,4]+X^{3}[4,2]$

$$
4,8<8,2+6,7
$$

Hasil akhir lintasan terpendek Floyd Warshall

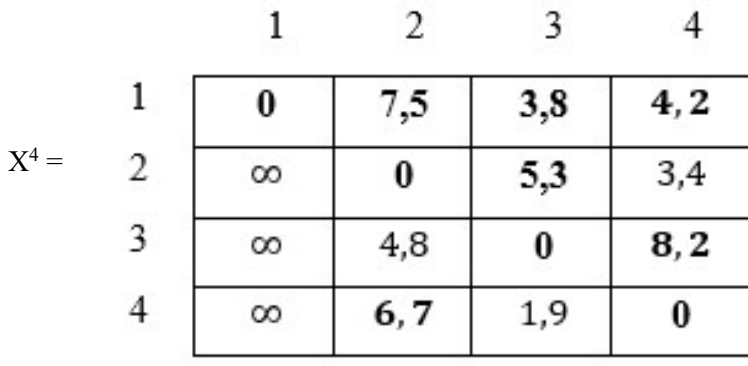

Gambar 13. Matriks akhir lintasan terpendek Floyd Warshall

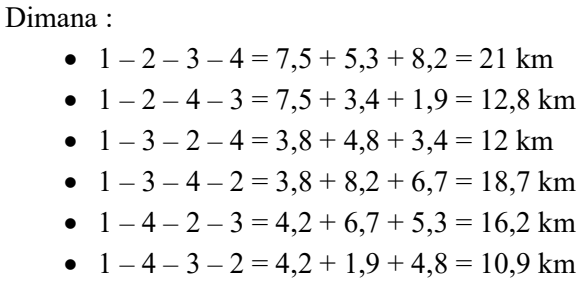

- $1-2-3-4=7,5+5,3+8,2=21 \mathrm{~km}$

- $1-2-4-3=7,5+3,4+1,9=12,8 \mathrm{~km}$

- $1-3-2-4=3,8+4,8+3,4=12 \mathrm{~km}$

- $1-3-4-2=3,8+8,2+6,7=18,7 \mathrm{~km}$

- $1-4-2-3=4,2+6,7+5,3=16,2 \mathrm{~km}$

- $1-4-3-2=4,2+1,9+4,8=10,9 \mathrm{~km}$

Jadi, berdasarkan perhitungan secara manual menggunakan algoritma Floyd Warshall didapatkan rute terpendeknya adalah 14-3-2 yaitu sebesar 10,9 km. Itu artinya rute terpendek yang dipilih dari posisi teknisi saat ini adalah posisi awal - BTS $46-$ BTS 21 - BTS 18 yaitu sejauh 10,9 km. Hasil rute terpendek yang dihasilkan menggunakan perhitungan manual menghasilkan rute yang sama dengan rute terpendek yang dihasilkan aplikasi seperti pada gambar 6 yaitu dari posisi awal - BTS 46 (Jl. Kapten A. Rivai) - BTS 21 (Jl. Angkatan 45) - BTS 18 (Jl. Orde Baru/ wilayah di sekitar Jl. Jend. Basuki Rachmad).

\section{KESIMPULAN DAN SARAN}

\subsection{Kesimpulan}

Dari penelitian ini didapatkan kesimpulan sebagai berikut :

1. Tampilan desain pada aplikasi sudah sesuai dengan perancangan tampilan, baik pada tampilan menu input nama BTS maupun pada menu Floyd Warshall.

2. Proses penentuan rute terpendek pada aplikasi telah berhasil, karena menghasilkan indikator yang sama antara hasil penentuan rute terpendek yang dihasilkan aplikasi dengan hasil perhitungan secara manual yang dihasilkan teori Floyd Warshall. Dimana rute terpendek yang dihasilkan algoritma Floyd Warshall untuk menuju BTS 18, BTS 21 dan BTS 46 adalah 14-3-2 yaitu sebesar 10,9 km.

\subsection{Saran}

1. Aplikasi ini membutuhkan kualitas jaringan internet telepon seluler yang baik agar dapat mengakses rute terpendek.

2. Penggunaan aplikasi ini lebih optimal apabila digunakan diluar gedung/bangunan, agar GPS lebih akurat dalam mendeteksi posisi saat ini. 


\section{DAFTAR PUSTAKA}

[1] PT. GCI Indonesia. "Products \& Services" Internet : http://www.gcidesign.co.id/index.php/products/, [Aug 12, 2018]

[2] B. Yulianto et al., "Location based services: positioning techniques," Provider, vol. 12, no. 1, pp. 4982-4987, 2010.

[3] D. T. Salaki, "Penentuan Lintasan Terpendek dari FMIPA ke Rektorat dan Fakultas lain di UNSRAT Manado menggunakan Algoritma Djikstra," Ilm. Sains, vol. 11, no. Djikstra, pp. 73-76, 2011.

[4] J. T. Informatika, F. Teknik, and U. H. Oleo, "Aplikasi pencarian rute terpendek apotek di kota kendari menggunakan algoritma," vol. 3, no. 1, pp. 9-16, 2017.

[5] R. M and R. F. Uzzy, "Penentuan Jalur Terpendek Menuju Cafe Di Kota Malang Menggunakan Metode Bellman-Ford dengan Location Based Service Berbasis Android," J. Ilm. Teknol. dan Inf. ASIA, vol. 8, no. 2, pp. 49-64, 2014.

[6] M. S. Handaka, "Perbandingan Algoritma Dijkstra ( Greedy ), Bellman-Ford ( BFS-DFS ), dan FloydWarshall (Dynamic Programming) dalam Pengaplikasian Lintasan Terpendek pada LinkState Routing Protocol," 2011.

[7] M. K. Ni Ketut Dewi Ari Jayanti, "Letak Parkir," Semin. Nas. Inform., pp. 75-81, 2014.

[8] R. Aprian and D. Novandi, "Perbandingan Algoritma Dijkstra dan Algoritma Floyd-Warshall dalam Penentuan Lintasan Terpendek ( Single Pair Shortest Path )," pp. 1-5, 2007.

[9] R. Saputra, "Sistem Informasi Geografis Pencarian Rute Optimum Obyek Wisata Kota Yogyakarta Dengan Algoritma Floyd-Warshall," J. Mat., vol. 14, pp. 19-24, 2011.

[10] K. Surendro, "Pemanfaatan Enterprise Architecture Planning Untuk Perencanaan Strategis Sistem informasi," J. Inform., vol. 8, no. 1, pp. 1-9, 2007.

[11] F. Mahdia and F. Noviyanto, "Pemanfaatan Google Maps API untuk Pembangunan Sistem Informasi Manajemen Bantuan Logistik Pasca Bencana Alam Berbasis Mobile Web (Studi Kasus : Badan Penanggulangan Bencana Daerah Kota Yogyakarta )," J. Sarj. Tek. Inform., vol. 1, no. 1, pp. 162-171, 2013.

\section{NOMENKLATUR}

Adapun nomenklatur dari semua persamaan matematika dalam penelitian ini antara lain :

l arti dari titik/node awal pada lintasan graf

j arti dari titik/node akhir pada lintasan graf

\section{BIODATA PENULIS}

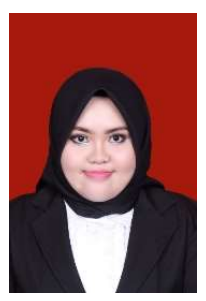

Vera Apriliani Nawagusti

Vera, dilahirkan di Baturaja, 7 April 1997, mahasiswi aktif Teknik Elektro, Program Studi Teknik Telekomunikasi, Politeknik Negeri Sriwijaya. 